\title{
Effects of shade from multiple kelp canopies on an understory algal assemblage
}

\author{
R. P. Clark ${ }^{1,2, *}$, M. S. Edwards ${ }^{1,3}$, M. S. Foster ${ }^{1}$ \\ ${ }^{1}$ Moss Landing Marine Laboratories, 8272 Moss Landing Road, Moss Landing, California 95039, USA \\ Present addresses: ${ }^{2}$ California Coastal Commission, 725 Front Street, Suite 300 Santa Cruz, California 95060, USA \\ ${ }^{3}$ Department of Biology, San Diego State University, San Diego, California 92182, USA
}

\begin{abstract}
We examined the effects of shade from multiple kelp canopy layers (surface Macrocystis pyrifera canopy, understory Pterygophora californica canopy), both individually and in combination, on an understory algal assemblage in a central Californian kelp forest. The removal of both kelp canopies resulted in a dense recruitment of the understory brown alga Desmarestia ligulata that formed a third canopy layer, which significantly decreased bottom light and the abundance of understory red algae. We subsequently created an additional canopy treatment by removing this third canopy layer. In general, the understory red algae fluctuated seasonally with winter swell intensity, changes in kelp canopy cover, and grazing; and although species richness increased significantly with increased bottom light, red algal bottom cover did not respond significantly to the canopy clearings until 2 yr after the canopies were initially cleared. Red algal cover within the Pterygophora canopy treatment was similar to that in the control treatment. In the absence of Pterygophora, the Macrocystis canopy treatment and 'no canopy' treatment were found to have greater red algal cover and species richness. Individual understory species were rare, which resulted in small effects sizes and thus low statistical power. However, when grouped post hoc, according to how they responded to the canopy clearings (i.e. response groups), we were able to detect canopy treatment effects as much as 1 yr earlier. This method identified that some understory red algae adapted to areas of canopy removal (light-adapted), and others adapted to a variety of light regimes (shade-tolerant). We were able to classify the light-adapted algae into 2 subgroups: the high-light species and the intermediate-light species. Although this method of grouping was done post hoc, our results indicate that it may provide the clearest assessment of how understory algae respond to shading from kelp canopies.
\end{abstract}

KEY WORDS: Canopy shading $\cdot$ Community structure $\cdot$ Kelp forest $\cdot$ Light-adapted $\cdot$ Macrocystis $\cdot$ Pterygophora $\cdot$ Red algae $\cdot$ Shade-tolerant

\section{INTRODUCTION}

Competitive dominance by canopy-forming plants plays an important role in structuring forest communities (Brokaw \& Scheiner 1989, Connell 1989, Spies \& Franklin 1989, Hubbell et al. 1999). Disturbancemediated removal of only a few canopy dominants can therefore prevent the competitive exclusion of many understory species, promoting greater diversity (Pickett \& White 1985, Brokaw \& Scheiner 1989, Whitmore 1989). In temperate marine communities, where shading by thick canopies of kelp (order: Laminariales) can, in part, regulate understory algal abundance in shallow $(<30 \mathrm{~m})$ water (Pearse \& Hines 1979, Foster 1982, Reed \& Foster 1984, Kennelly 1987a, Harrold et al. 1988, Dayton et al. 1992), the removal of the dominant 
kelp canopies typically results in increased bottom light and a corresponding increase in the abundance of opportunistic species (Dayton et al. 1984, 1992, Reed \& Foster 1984, Kennelly 1987b, Cecchi \& Cinelli 1992, Graham 1996, Edwards 1998). As a consequence, variation in algal assemblages within and among kelp forests can be attributed partly to differences in the primary canopy-disturbing agent, ocean wave exposure (Foster 1975a,b, Cowen et al. 1982, Foster 1982, Dayton et al. 1984, 1992, Breda \& Foster 1985, Harrold et al. 1988, Seymour et al. 1989, Graham 1997). Along parts of the west coast of North America, where large ocean waves associated with winter storms typically result in maximum kelp canopies in summer and minimum canopies in winter (Kimura \& Foster 1984, Reed \& Foster 1984, Dayton et al. 1992), competitive interactions between the canopy-forming kelps and understory algae can vary temporally, further increasing the overall variation in kelp forest community composition (Pearse \& Hines 1979, Gerard 1984, Kennelly 1987a,b, Harrold et al. 1988, Dayton et al. 1999).

Given that understory algal assemblages are commonly complex mosaics of multiple species, responses to environmental perturbations can be ambiguous, especially where these responses vary among species. Furthermore, many understory algal assemblages contain numerous rare species that, when examined individually, may show only small (possibly undetectable) responses to environmental perturbations. As a consequence, many studies on the effects of shading by kelp canopies have simplified matters by limiting their focus to either the most common species (e.g. Edwards 1998, Dayton et al. 1999) or groups of species (e.g. Reed \& Foster 1984, Santelices \& Ojeda 1984, Kennelly 1987b, 1989). One method commonly used for grouping species has been to combine those with similar morphologies (e.g. foliose red algae vs articulated coralline algae; Littler \& Littler 1980, Reed \& Foster 1984, Dayton et al. 1999). Although this 'functional group' approach (sensu Littler \& Littler 1980) may simplify patterns in complex multi-species systems, it may be inappropriate if the ecologies of the various species within each group differ substantially (Padilla \& Allen 2000). In such cases, it may be better to group species according to similarities in how they respond to changes in a particular aspect of their environment. This 'ecological-response group' approach has been widely used by terrestrial plant ecologists to classify individual species according to how they respond to changes in their light environment and has been very useful in studies on canopy shading (e.g. Collins et al. 1985, Whitmore 1989, Kursar \& Coley 1999).

The logic behind the response-group approach is straightforward; if canopy shading regulates an understory assemblage, canopy removal should elicit posi- tive responses in recruitment and/or growth for species that require high irradiances, negative responses for species that require low irradiances, and no responses for species adapted to a variety of irradiances (Brokaw \& Scheiner 1989, Spies \& Franklin 1989, Whitmore 1989, Kursar \& Coley 1999). Those species, then, that remain rare under dense canopies but rapidly recruit into canopy gaps following widespread canopy removal, have typically been referred to as 'lightadapted', 'gap-requiring' or 'shade-intolerant' and are often considered to represent fugitive species. On the other hand, those species that occur under forest canopies but do not markedly respond to canopy loss have typically been referred to as 'light-flexible' or 'shade-tolerant' species and are often considered to represent climax species (Whitmore 1989). Whereas light-flexible species are generally numerically more abundant than light-adapted species, both under canopies as well as in canopy gaps, their ability to withstand low-light environments may result in a decreased ability to rapidly respond to sudden increases in light (Canham 1989). As a consequence, light-adapted species, through greater recruitment and growth, typically dominate areas following canopy loss. There are numerous examples of response groups for terrestrial plants which have been used successfully in marine systems to discern the effects of physical disturbance on understory algae (Hay 1994). Other examples can be discerned from published studies of marine macroalgal assemblages (e.g. Pearse \& Hines 1979, Kastendiek 1982, Santelices \& Ojeda 1984, Edwards 1998), but this approach has not been widely applied. Classification of response groups may be particularly useful for grouping understory algae in subtidal kelp forests where, due to the synergistic effects of a floating surface canopy and a stipitate understory canopy, light regimes are highly variable in space and time (Reed \& Foster 1984, Edwards 2004, the present study).

Along the Californian coast, thick surface canopies of the giant kelp Macrocystis pyrifera (hereafter Macrocystis) and understory canopies of the stipitate kelp Pterygophora californica (hereafter Pterygophora) occur over rocky substrates from 2 to $>30 \mathrm{~m}$ depth (Foster \& Schiel 1985). Both individually and together, these canopies, along with the water column itself, can decrease bottom irradiance to $<1 \%$ of that at the surface and thereby reduce the abundance of understory algae (Reed \& Foster 1984, Edwards 1998). While numerous studies have examined the effect of shading from kelp canopies on understory algae, few have simultaneously examined the effects of shading from both individual and combined canopy layers (see however Reed \& Foster 1984, Dayton et al. 1999). Here, we investigate the effects of shading from individual 
and combined canopy layers on understory algae by manipulating Macrocystis and Pterygophora canopies over a 2 yr period in a central Californian kelp forest, and then examining changes in the abundance of understory algae. We show that while both assemblage-wide and individual species responses to the canopy manipulations may be small, certain groups of species within the understory assemblage may exhibit stronger responses than other groups due to differences in their adaptation to specific light regimes. These response-groups can then be used to elucidate otherwise cryptic responses in the understory algal assemblages to complex changes in the benthic light environment.

\section{MATERIALS AND METHODS}

Study site. The study was carried out in Stillwater Cove, California $\left(36^{\circ} 34^{\prime} \mathrm{N}, 121^{\circ} 56^{\prime} \mathrm{W}\right)$ from December 1991 to January 1994 (see Fig. 1). Stillwater Cove faces south and is relatively protected from the large northwest swells that are associated with winter storms, although less frequent southwest winter swells periodically reduce the surface Macrocystis canopies (Foster 1982, Kimura \& Foster 1984, Reed \& Foster 1984). These canopies typically recover during the following spring and become fully developed by mid to late summer. Thus, Macrocystis exhibits a seasonal cycle with a maximum surface canopy in summer and a minimum canopy in winter. A uniform understory canopy (1 to $2 \mathrm{~m}$ above the substratum) of Pterygophora is common in the cove and exhibits a similar but less pronounced seasonality to the Macrocystis canopy. The substratum beneath these canopies is dominated by a dense turf composed of several species of geniculate coralline algae, primarily Calliarthron tuberculosum and Bossiella californica, that covers almost all available substrate not occupied by kelp, the foliose red algae Plocamium cartilagineum and Laurencia subopposita, which commonly grow as epiphytes on the geniculate coralline algae, and a variety of brown algae, primarily Dictyoneuropsis reticulata, Cystoseira osmundacea, and the seasonal Desmarestia ligulata (Foster 1982, Reed \& Foster 1984, Konar \& Foster 1992, Leonard \& Clark 1993, Edwards 1998). Numerous other species of red macroalgae also occur in the cove but comprise only a small portion $(<1 \%$ individually and $<5 \%$ combined) of the understory assemblage.

Canopy clearing. In January 1992, Macrocystis and Pterygophora canopies were manipulated, both individually and in combination, at three 10 to $12 \mathrm{~m}$ deep sites within Stillwater Cove. Canopy clearings were established in an orthogonal block design (Fig. 1A). These sites were selected following a series of survey dives in December 1991 and were chosen based on the presence of both Macrocystis and Pterygophora canopies, a predominance of low-relief rock, and limited sand cover. The sites were initially established as $30 \mathrm{~m}$ radius circles around a center marker buoy, and were divided into 2 regions of equal area: a $20 \mathrm{~m}$ radius inner circle surrounded by a $10 \mathrm{~m}$ radius outer torus. Each region was subsequently divided in half and canopy-manipulation treatments were allocated within each section (Fig. 1B). After the initial December 1991 winter sampling (pre-treatment baseline), Macrocystis were cleared from each inner circle by

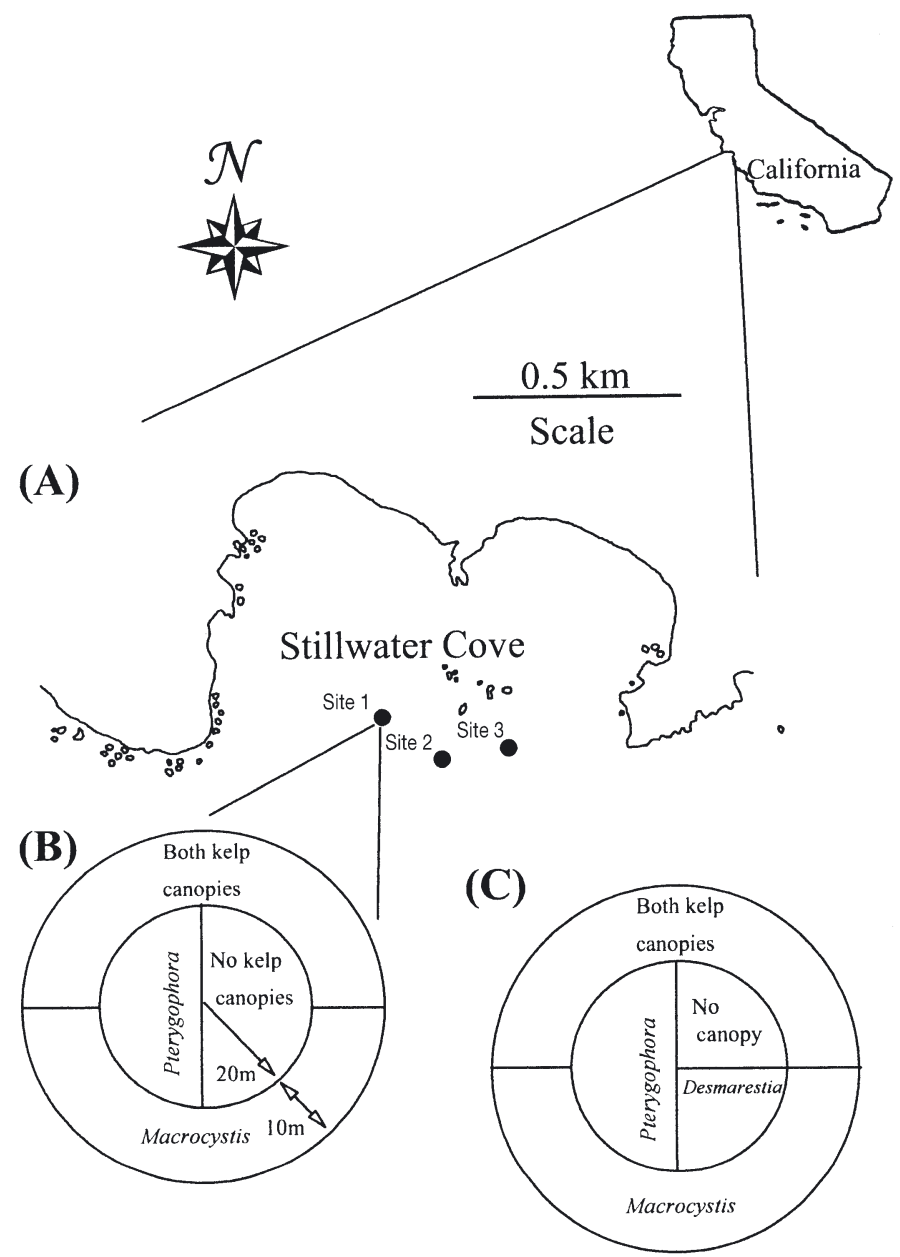

Fig. 1. (A) Study area at Stillwater Cove showing location of the 3 replicate sites. (B) Canopy clearing design showing the $20 \mathrm{~m}$ radius inner circles and $10 \mathrm{~m}$ radius outer tori. Canopy clearings were allocated in a blocked design. Treatments include 'no kelp canopies' = both Macrocystis and Pterygophora removed, 'Pterygophora canopy' = Macrocystis removed and Pterygophora left unmanipulated, 'Macrocystis canopy' = Pterygophora removed and Macrocystis left unmanipilated, and 'both canopies' = both kelp species left unmanipulated (also considered as control treatment). (C) Canopy clearings showing the placement of the Desmarestia removal (redefining the 'no canopy' treatment) and the 'Desmarestia canopy' $=$ Desmarestia left unmanipulated within the previous 'no kelp canopies' treatment 
cutting their stipes at their holdfasts below the primary dichotomy. Holdfasts were not removed in order to minimize disturbance to the substratum and no Macrocystis were removed from the outer tori. All Pterygophora were removed from half of each inner circle and half of each outer torus by cutting them at their holdfasts. Canopy treatments are hereafter referred to by the name of the kelp canopies present (i.e. Macrocystis canopy, Pterygophora canopy, no canopy and both canopies treatments; Fig. 1B). All canopy treatments were maintained for $2 \mathrm{yr}$ by removing all Macrocystis and Pterygophora recruits from their corresponding treatments before they formed a canopy. Giant kelp canopy abundance was then monitored from March 1992 to November 1993 by visually estimating kelp canopy abundance (expressed as wet weight) during aerial surveys (data provided by D. Glantz, Kelco, ISP Alginates, San Diego, CA).

In the summer following the initial canopy removal (June 1992), the seasonal understory alga Desmarestia ligulata (order: Desmarestiales; hereafter Desmarestia) developed a thick bottom cover (i.e. a third canopy layer) within the no kelp canopies treatment (see also Edwards 1998). To examine the effects of this third canopy layer on understory algae, all Desmarestia were cleared from half of each no kelp canopies treatment but were allowed to produce a thick seasonal canopy in the other half. This subdivided the no kelp canopies treatment into 2 treatments: a Desmarestia canopy treatment where Macrocystis and Pterygophora were both removed but Desmarestia remained, and a no canopy treatment where Macrocystis, Pterygophora and Desmarestia were all removed (Fig. 1C).

To quantify the difference in available light among treatments and sampling seasons, benthic irradiance was estimated at 6 positions within each canopy treatment during March, May and September 1993. Estimates were made at $5 \mathrm{~m}$ intervals along each of 3 radial transects within one of the replicate sites using a Li-Cor $4 \pi$ quantum sphere collector (sample rate $=2 \mathrm{~Hz}$ ) attached to a hand-held CTD (Seabird Electronics-Sea $\mathrm{Cat}^{\circledR}$ ). On each date, irradiance measurements were also made at 1 position within each canopy treatment at the other 2 replicate sites to check for consistency. All measurements were made on cloudless days at $\sim 1200 \mathrm{~h}$ and were averaged over 2 min intervals. Because surface irradiance differed among sample dates, it was necessary to standardize the irradiance values. The average benthic irradiance $\left(\mu \mathrm{E} \mathrm{m}^{-2} \mathrm{~s}^{-1}\right)$ within each treatment was standardized to that of the no canopy treatment (average treatment irradiance/average no canopy treatment irradiance) and expressed as 'percent ambient light'.

Holes within each kelp canopy (patch-gaps), associated with natural variability in kelp canopies, were estimated using the percent cover of Desmarestia, which requires close to full benthic irradiance to grow (Edwards 1998). The area influenced by patch-gaps was estimated as ' $\%$ cover of patch-gaps' $=\%$ cover Desmarestia for a treatment/\% cover of Desmarestia within the Desmarestia treatment (optimal cover) $\times$ $100 \%$.

Effects of the canopy clearing on understory algae. The abundance of understory algae was estimated within each canopy treatment seasonally from December 1991 to December 1993, except in the Desmarestia treatment where understory algae was first estimated in September 1992. A random point quadrat (RPQ) (Leonard \& Clark 1993) was used to identify algal species at 20 points within each of the 15 quadrats that were randomly placed in each canopy treatment during each season. This technique estimated the percent bottom cover of individual algal species to $5 \%$ resolution within each quadrat (Goodall 1952, Foster 1982, Greig-Smith 1983, Leonard \& Clark 1993). The percent bottom cover of individual species within each canopy treatment was determined at each site from these 15 quadrats, and the overall percent bottom cover of each species was then estimated for each canopy treatment from the 3 sites $(\mathrm{n}=3)$. The December 1991 sampling estimated initial algal bottom cover prior to canopy manipulations. Total algal bottom cover within a quadrat often exceeded $100 \%$ due to layering.

Because RPQs often underestimate rare species $(<1 \%$ cover) (Dethier et al. 1993, Leonard \& Clark 1993), we measured how frequently rare species occurred within 18 to $0.25 \mathrm{~m}^{2}$ quadrats that were randomly placed in each canopy treatment. Here, individual species were classified as being either present or absent in each quadrat and their frequency of occurrence then determined by dividing the number of quadrats in which each species occurred by the total number of quadrats sampled (Greig-Smith 1983). This technique offered an additional estimate of community structure (species richness), which was estimated both as average number of species observed per quadrat, and as the total number of species per canopy treatment.

Response groups. Individual understory algal species generally occurred in low abundances $(<5 \%$ bottom cover) in all canopy treatments and continued to do so throughout the study. As a result, statistical power to detect changes in abundance for any one species following canopy removal was consistently problematic (see 'Results'). Therefore, to increase our ability to discern otherwise weak canopy effects, we combined individual species into larger groups, which were subsequently examined for changes in (combined) bottom cover. We first grouped all understory species together (i.e. total red algae), and then classified species post hoc according to similarities in the 
way they responded to the canopy manipulations. As has been observed in terrestrial forests, this latter method yielded 2 response groups: light-adapted and light-flexible species. Individual species were considered to be light-adapted if they exhibited a response in cover which resulted in there being at least twice the bottom cover in the no canopy treatment as that of the both kelp canopy treatment in September 1993. The rarity of many of the species mandated this approach, rather than a statistical one. Species were considered to be light flexible if they occurred in all canopy treatments but did not respond (greater than twice the control) following any of the canopy removals. To identify possible subgroups within the light-adapted group (e.g. those species that responded differently to the removal of a single canopy layer than to the removal of both canopy layers), the light-adapted species were further divided into 2 subgroups: high-light-adapted species and intermediate-light-adapted species. Algae were considered high-light species if they increased (greater than twice the control) following the removal of both kelp canopies but not following the removal of only a single canopy, and intermediate-light species if they increased following the removal of either kelp canopy alone as well as both kelp canopies together.

We examined how each group changed in the canopy treatments over the course of the study (1991 to 1993). We are careful to point out that this responsegroup classification scheme was developed from evaluating changes in species abundance post hoc, and is therefore not intended to make generalizations about the ecology of any one species, but rather to simplify a number of complex responses in multiple species to the experimental treatments. If the interest is in examining the ecology of any one species in this study, proper unbiased experimental protocols need to be followed. We do, however, pose these groups as a means of elucidating how the understory algal assemblage in our study sites changed following canopy manipulation, and suggest that they can be used to increase statistical power in future studies.

Statistical analyses. All statistical analyses were done using SYSTAT (Windows version 8.0). Prior to analyses, data were examined for homogeneity of variances using an $F$-test or Cochran's $C$-test, and for normality by graphical examination of residuals. If percent cover data were heteroscedastic they were arcsine transformed (Arcsine $\sqrt{x+1}$ ) and retested. There is increasing risk of making a Type I error when inferences are simultaneously drawn from multiple statistical tests (Peres-Neto 1999). Therefore, in cases where this was done (e.g. a priori treatment contrasts following ANOVA), we applied the Bonferroni method of controlling for error inflation (Simes 1986). However, in cases where separate statistical tests were per- formed on individual species or for different dates, and where the inferences drawn for these tests were independent, we adopt the argument of McCullagh \& Nelder (1989), Hilborn \& Mangel (1997) and Dayton et al. (1999) and do not correct for $\alpha$-error inflation. Given the rarity of individual species, the statistical power of detecting differences among the canopy treatments for any one species or group was considered to be inherently low, and the corresponding $\alpha$-error reduction would too greatly increase the risk of making a Type II error. We, however, report the uncorrected p-values, degrees of freedom and mean square estimates and allow the reader to decide for themselves the relative importance of Type I versus Type II errors, as well as evaluate the significance of each test accordingly.

To determine if kelp canopy removal affected the bottom cover of individual understory species or the combined bottom cover of the different algal groups, separate 1-way blocked ANOVAs, with canopy treatment blocked within site, were done for each species and algal group on each survey date. The effects of different canopy treatments on individual species and algal groups were tested by contrasting algal bottom covers within each canopy treatment to that in the appropriate control using Bonferroni-adjusted planned comparisons. On each sample date, the Macrocystis canopy, Pterygophora canopy and no canopy treatments were each compared to the both canopies treatment, while the Desmarestia canopy treatment was compared to the no canopy treatment.

\section{RESULTS}

\section{Canopy clearing and bottom irradiance}

Bottom irradiance within the no canopy treatment (hereafter referred to as ambient light) was used to represent available bottom light and was the standard against which light levels in the other treatments were compared. Percent of ambient light in all other canopy treatments was greatest in late winter to early spring when kelp canopies were at their minimum, and then decreased during the summer and fall (Fig. 2) as kelp canopies recovered from the winter storms (Fig. 3A). Specifically, the Macrocystis canopy alone was capable of reducing bottom light to $~ 60 \%$ of ambient during the spring and $\sim 45 \%$ of ambient during the fall, while the Pterygophora canopy, either alone or in combination with the Macrocystis canopy, was capable of reducing bottom light to $\sim 25 \%$ of ambient during the spring and $\sim 2 \%$ of ambient during the fall. Finally, although it only occurred seasonally (spring to fall), the Desmarestia canopy alone had the greatest effect on bottom light, decreasing bottom light to $<1 \%$ of ambient by the fall 


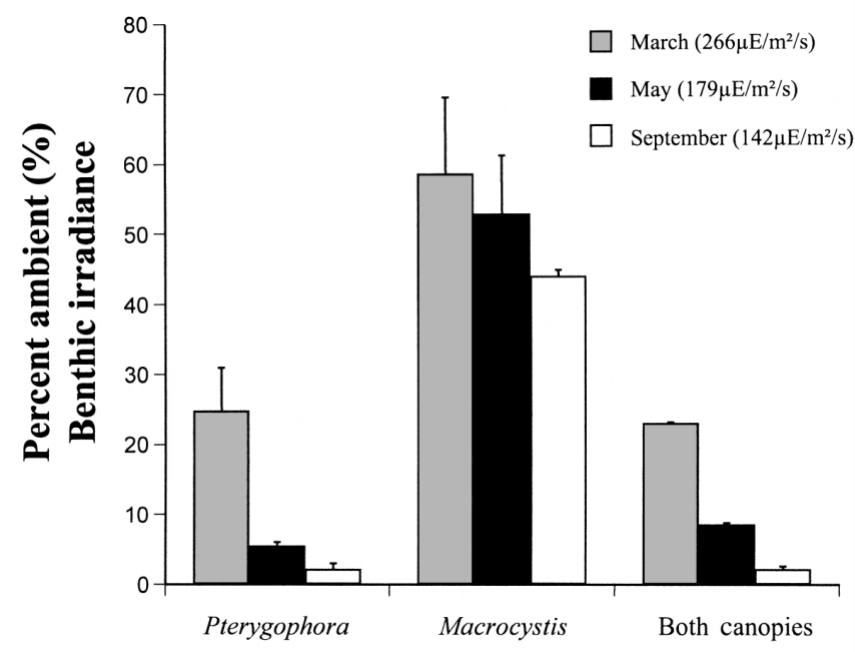

Fig. 2. Percent of ambient bottom light (mean + SE) under each canopy type individually and combined throughout the summer growth season. Data represent the amount of light relative to that observed at the same depth in the no canopy treatment (provided as $\mu \mathrm{E} \mathrm{m}^{-2} \mathrm{~s}^{-1}$ ). Kelp species identified refers to the canopy present in that treatment $(n=4)$

when its cover was at a maximum (see also Edwards 1998). Furthermore, spatial heterogeneity in bottom light (i.e. differences in benthic irradiance among sample positions along each transect) within each area varied significantly among the 4 canopy treatments in the spring and summer (Cochran's tests: $\mathrm{p}<0.05$ and 0.01 respectively, $\mathrm{n}=5, \mathrm{df}=4$ ) but not in the fall (Cochran's tests: $p>0.05$ ). Spatial heterogeneity in bottom light (as estimated by standard error) declined markedly in the summer and fall, indicating that patch-gaps (areas within each canopy treatment with greater irradiance than the surrounding area which likely resulted from beaks in the canopy; Connell 1989) decreased in size and number for each canopy treatment as the kelp canopies became more established (Fig. 2).

\section{Effects of the canopy clearing on understory algae}

The most conspicuous biological response to the canopy manipulations was a large springtime recruitment of the annual alga Desmarestia into the areas cleared of all kelp canopies. As a result, Desmarestia bottom cover varied significantly among the 4 canopy treatments in September 1992 (ANOVA: $F=7.07$; df $=$ 3,$6 ; \mathrm{p}=0.018$; Fig. 3B). Specifically, bottom cover was significantly or near significantly greater in the no canopy treatment (Bonferroni: no canopy vs both canopies, $\mathrm{p}=0.021$; no canopy vs Macrocystis canopy, $\mathrm{p}=0.058$; no canopy vs Pterygophora canopy, $\mathrm{p}=$ 0.032 ) but was not significantly different between any of the other pairs of canopy treatments. However, there was a trend in which Desmarestia bottom cover appeared greater in the Pterygophora canopy treatment than in the Macrocystis canopy treatment, both of which appeared greater than in the both canopies treatment (Fig. 3B). The general effect of the Desmarestia canopy was 2-fold: first it reduced benthic light by greater than $99 \%$ relative to adjacent areas without Desmarestia, and second it reduced the size and branch density of at least one of the more common understory red alga, Plocamium cartilagineum, through physical abrasion (Clark 1996).

\section{Total red algae}

Total red algal abundance varied seasonally within Stillwater Cove, exhibiting maximum bottom cover in the spring and minimum cover in the winter (Fig. 3C). Following its spring maximum, total red algal cover declined in all canopy treatments between June and September each year (Fig. 3C), coincident with increasing kelp canopies (Fig. 3A). These declines were particularly large in 1992, apparently enhanced by intense grazing from large numbers (400 to 500 ind. site $^{-1}$ ) of the Opistobranch Aplysia californica (R. P. Clark pers. obs.; Fig. 3C). Following the A. californica outbreak (A. californica densities declined by January 1993; R. P. Clark pers. obs.), total red algal abundance increased in all canopy treatments, returning to premanipulation cover by June 1993, before again decreasing in all but the no canopy treatment as the canopies again approached their annual maximum (Fig. 3C). Total red algal cover in the no canopy treatment continued to increase through December 1993. Surprisingly, however, differences in total red algal cover between the canopy treatments were significant only on the last sample date (December 1993; ANOVA: $F=4.09 ; \mathrm{df}=4,8 ; \mathrm{p}=0.043$ ) (Table 1a, Fig. 3C). At this time, total red algal cover was significantly greater in the no canopy treatment $(43 \pm 6 \%$, mean $\pm \mathrm{SE})$ than in the both canopies treatment $(24 \pm 5 \%$; Bonferroni: $\mathrm{p}=$ $0.05)$ and the Pterygophora canopy treatment $(22 \pm$ $5 \%, \mathrm{p}=0.03$ ) but was not significantly different than in the Macrocystis canopy treatment $(33 \pm 6 \%, p=0.5)$, again suggesting that the Macrocystis canopy alone was less efficient at reducing benthic irradiance than either the Pterygophora canopy alone or both canopies combined. The overall lack of significant canopy effects across sample dates, however, was surprising given the large body of literature suggesting that kelp canopies exert significant effects on understory algae (e.g. Foster 1975a,b, Foster 1982, Reed \& Foster 1984, Kenelly 1987a, Harrold et al. 1988, Dayton et al. 1992), and we therefore examined species responses individually as well as for potential response-groups. 

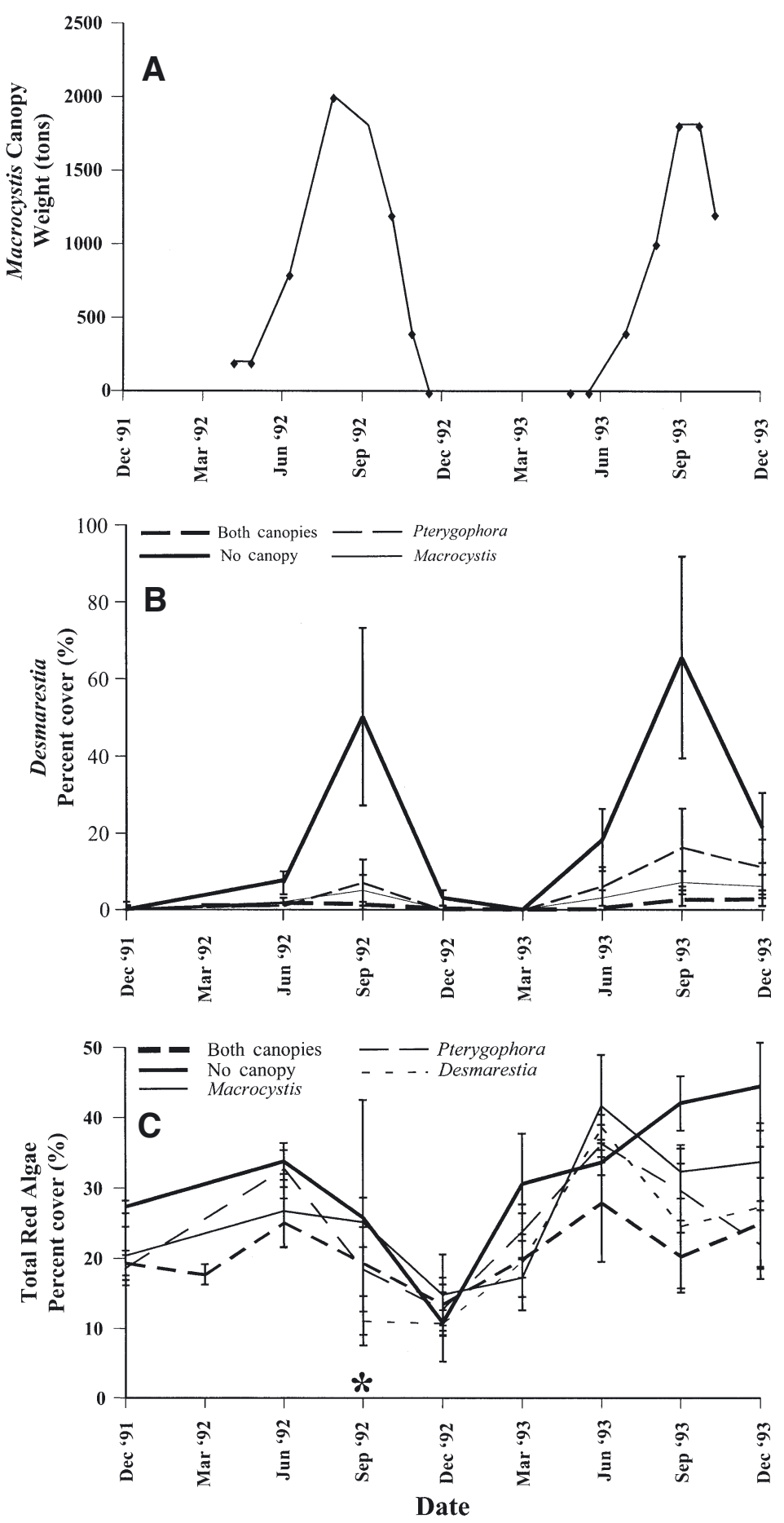

Fig. 3. (A) Kelp canopy abundance in Stillwater Cove during study period (March 1992 to December 1993). Data for kelp abundance are presented as wet weight (tons) for the surface Macrocystis pyrifera canopy as estimated from aerial surveys by D. Glantz (ISP Alginates, San Diego, CA) and are used to show relative changes in canopy abundance. (B) Bottom cover of Desmaretia ligulata in the canopy treatments (mean $\pm \mathrm{SE}$ ). Data were determined as the average bottom cover per canopy treatment in the 3 sites $(n=3)$. (C) Bottom cover (mean $\pm \mathrm{SE}$ ) of understory red algae (as a group) in the different canopy treatments (December 1991 to December 1993). Data for the Desmarestia canopy treatment begin in September 1992, following the removal of the Desmarestia canopy $(\mathrm{n}=3)$. Note the asterisk denoting the time of intense Aplysia grazing

\section{Individual species}

With few exceptions, we were unable to detect statistically significant responses of individual understory species to the canopy manipulations (Table 1b). We attributed this surprising result, at least in part, to low statistical power resulting from the small effect sizes caused by the rarity of individual species, even though some species had proportionally large changes in bottom cover relative to the both canopies treatment (Table 2). In fact, in September 1993, all species except Plocamium cartilagineum, Laurencia subopposita, Callophyllis crenulata. and geniculate corallines exhibited their greatest bottom cover in the no canopy treatment and their lowest cover in the both canopies treatment (Table 3). Similarly, species richness was also highest in the no canopy treatment (Table 3). In contrast, the availability of bare space (i.e. rock and nongeniculate coralline algae) was greatest in the both canopies treatment and lowest in the no canopy treatment (excluding the Desmarestia canopy treatment where bare space was difficult to measure due to the dense cover of Desmarestia; Table 3). The effects of the canopy manipulations on the rare understory species, which are commonly underrepresented using a point quadrat method, were analyzed separately based on their frequencies of occurrence (see section Rare species and richness).

\section{Response groups}

Changes in cover of individual understory species in each of the canopy treatments were assessed post hoc in September 1993 and the species then regrouped according to how they responded to the canopy manipulations. Grouping the individual species in this manner yielded 2 general response groups, light-adapted species and light-flexible species (Table 2), and identified canopy treatment effects up to 8 mo earlier than did the total red algae or individual species approaches (Table 1a-c). Specifically, responses to the canopy manipulations for the total red algae group (Table 1a) were not observed to be statistically significant until December 1993, whereas responses for the light-adapted species were observed as early as March 1993 (Table 1c). At that time, bottom cover of light-adapted species was significantly greater in the no canopy treatment than in the Desmarestia canopy treatment (Bonferroni: $\mathrm{p}<0.01$ ), the both canopies treat- 


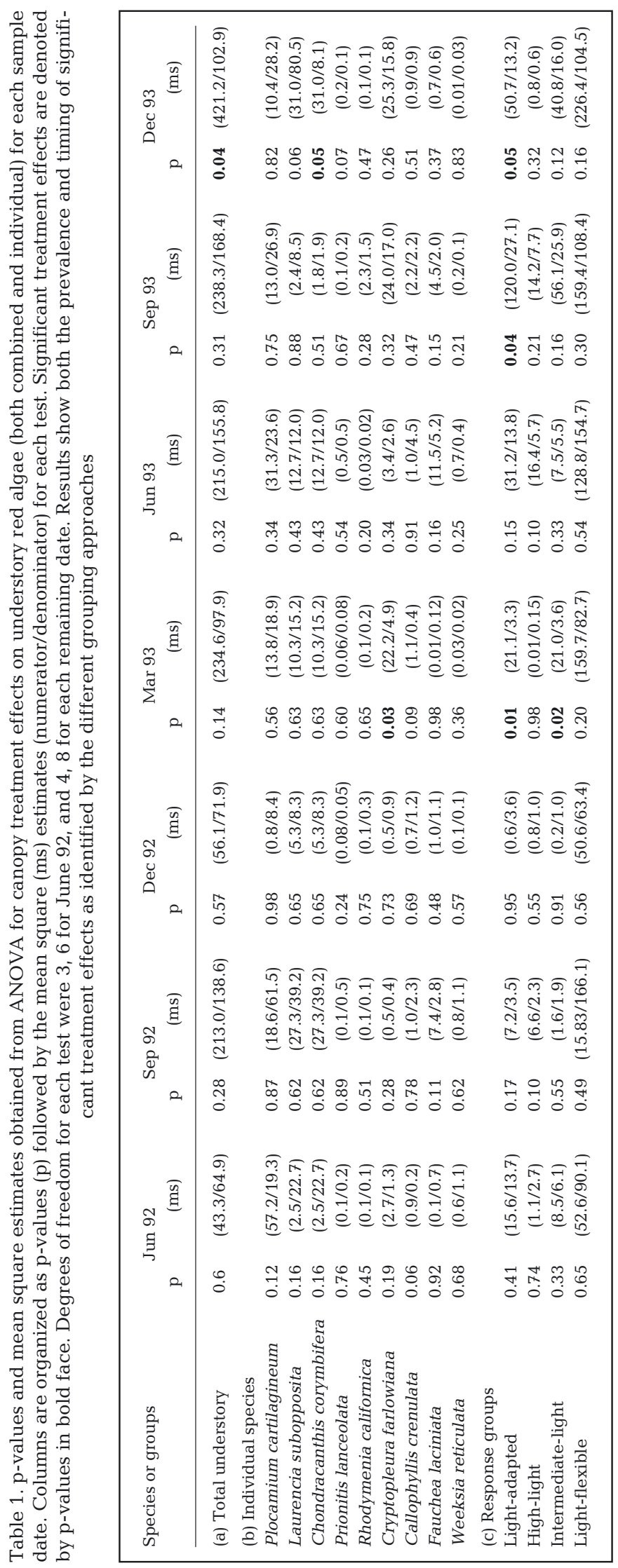

ment $(\mathrm{p}=0.05)$ and the Pterygophora canopy treatment $(p=0.05)$, and was significantly greater in the Macrocystis canopy treatment than in the Desmarestia canopy treatment $(p=0.048)$. Bottom cover, however, did not differ between any of the other canopy treatments. In contrast, canopy treatment effects were not observed for the light-flexible group on any of the sample dates (Table 1c). We are careful to point out that this method was done post hoc and that intentionally grouping those species with the greatest responses, and then statistically testing the response of this group to the canopy manipulations will undoubtedly result in artificially high power and therefore should be viewed with caution. However, we think this method elucidated otherwise weak or cryptic responses by certain algae that responded in consort to the canopy manipulations, while other algae did not. Furthermore, this method allowed us to quantitatively assess the magnitude of these different responses, and therefore can provide critical information into the overall responses by the understory assemblage that would otherwise not have been determined.

Within the light-adapted group, differences in the way the individual species responded to the canopy treatments suggested that 2 subgroups could be discerned: high-light species and intermediate-light species. High-light species were those that only responded to removal of all canopy layers, while intermediate-light species were those that responded to removal of either kelp canopy layer as well as all (including Desmarestia) canopy layers (Table 2), and ultimately exhibited at least twice the bottom cover in the corresponding canopy treatment than in the both canopies treatment (Table 3). Dividing the lightadapted group into these subgroups differentiated responses to the canopy treatments for the high-light species in September 1992 and the intermediate-light species in March 1993 (Table 1c). This grouping method identified responses to the canopy treatments as much as a year earlier than for any of the other grouping methods and identified responses on at least 3 sample dates when none of the other methods did (Table 1a-c). Furthermore, it suggested that some species were strongly affected by canopy shading, some species were weakly affected by shading, and some species were unaffected by shading.

\section{Rare species and richness}

Although numerous understory species occurred in the study sites in consistently low abundances during this study, only 2 were classified as rare. Cover of these, Fryeella gardneri and Neoptilota densa, never exceeded $1 \%$ in any of the canopy treatments, making 
Table 2. Understory algal response groups based on percent cover relative to the both kelp canopies treatment in September 1993. Relative percent cover (treatment \% cover/both kelp canopies \% cover) represents the response of each alga or group to the corresponding treatment, compared to the control treatment. Light-adapted species responded to the clearing of 1 or more canopies (greater than twice the control). Maximum light species responded when both canopies layers were cleared. Intermediate light species responded when 1 or more canopy layers were cleared. Light-flexible species have cover approximately equal to the controls

\begin{tabular}{|lrcc|}
\hline \multirow{2}{*}{ Light requirement categories } & \multicolumn{3}{c|}{ Relative percent cover } \\
& No canopy & Macrocystis & Pterygpophora \\
\hline Light adapted (combined) & 5.8 & 2.5 & 2.4 \\
High light spp. (combined) & 4.7 & 1.1 & 0.7 \\
Fauchea laciniata & 28.0 & 2.0 & 1.0 \\
Chondracanthus corymbiferus & 3.1 & 0.6 & 0.6 \\
Prionitis lanceolata & 2.0 & 1.3 & 0.3 \\
Weeksia reticulata & 2.7 & 1.8 & 1.4 \\
Intermediate light spp. (combined) & 6.5 & 3.5 & 3.5 \\
Callophyllis crenulata & 5.7 & 7.0 & 8.0 \\
Rhodymenia californica & 7.0 & 3.0 & 2.5 \\
Cryptopleura farlowiana & 6.5 & 2.9 & 2.9 \\
Light-flexible spp. (combined) & 1.1 & 1.1 & 1.2 \\
Plocamium cartilagineum & 1.4 & 1.6 & 1.4 \\
Laurencia subopposita & 1.3 & 1.3 & 1.2 \\
Geniculate corallines & 1.0 & 1.0 & 1.2 \\
\hline
\end{tabular}

them too rare to be included in any of the algal groups with confidence (Table 3). Instead, these species were included in the estimation of species richness in each canopy treatment, both for the average number of species per unit area (sample quadrat) as well as the total number of species observed per canopy treatment. The number of species observed per unit area differed significantly among the canopy treatments (ANOVA: $p<0.01$ ), with the no canopy treatment $>$ the Macrocystis canopy treatment $>$ the Pterygophora canopy treatment $>$ the both canopies treatment $>$ the Desmarestia canopy treatment (Table 3). In addition, the total number of species observed in each canopy treatment followed a similar pattern with the no canopy treatment $>$ the Macrocystis canopy treatment $>$ the Pterygophora canopy treatment $=$ the both canopies treatment $=$ the Desmarestia canopy treatment (Table 3). Together, these 2 measures indicated that spe-

Table 3. Percent bottom cover of understory algae in each canopy treatment in September 1993 (fleshy red algae = total red algae-geniculate corallines). Significant differences of blocked ANOVA: ns = not significant. na $=$ not applicable, nd $=$ not determined, ns = not significant. Bold face indicates treatments with the highest value for each category. Species richness and percent patch gaps determined as described in text

\begin{tabular}{|c|c|c|c|c|c|c|c|}
\hline \multirow[b]{2}{*}{$\begin{array}{l}\text { Canopy treatment } \\
\% \text { surface irradiance }\end{array}$} & \multicolumn{5}{|c|}{$\ldots$ cover by canopy treatment } & \multicolumn{2}{|c|}{ Effect } \\
\hline & $\begin{array}{c}\text { No canopy } \\
9.10 \%\end{array}$ & $\begin{array}{c}\text { Macrocystis } \\
4.00 \%\end{array}$ & $\begin{array}{c}\text { Pterygophora } \\
0.20 \%\end{array}$ & $\begin{array}{c}\text { Desmarestia } \\
0.02 \%\end{array}$ & $\begin{array}{c}\text { Both canopies } \\
0.20 \%\end{array}$ & Treatment & Site (block) \\
\hline Fleshy red algae combined & 41.8 & 32.9 & 29.3 & 24.9 & 20.2 & ns & $<0.05$ \\
\hline Plocamium cartilagineum & 13.6 & 15.7 & 13.6 & 11.3 & 9.9 & ns & $<0.05$ \\
\hline Laurencia subopposita & 8.1 & 8.2 & 7.4 & 6.3 & 6.4 & ns & $<0.05$ \\
\hline Chondracanthus corymbifera & 2.2 & 0.4 & 0.4 & 0.7 & 0.7 & $\mathrm{~ns}$ & ns \\
\hline Prionitis lanceolata & 0.6 & 0.4 & 0.1 & 0.1 & 0.3 & $\mathrm{~ns}$ & $\mathrm{~ns}$ \\
\hline Rhodymenia californica & 2.8 & 1.2 & 1 & 1.2 & 0.4 & ns & $\mathrm{ns}$ \\
\hline Cryptopleura farlowiana & 9.1 & 4 & 4 & 3.6 & 1.4 & $<0.1$ & $<0.05$ \\
\hline Callophyllis crenulata & 1.7 & 2.1 & 2.4 & 1 & 0.3 & ns & ns \\
\hline Fauchea laciniata & 2.8 & 0.2 & 0.1 & 0 & 0.1 & ns & $\mathrm{ns}$ \\
\hline Weeksia reticulata & 0.6 & 0.4 & 0.3 & 0.2 & 0.22 & ns & ns \\
\hline Geniculate corallines & 63.3 & 67.5 & 76.9 & 75.9 & 64.3 & ns & $<0.05$ \\
\hline Rare species & 0.4 & 0.2 & 0 & 0.1 & 0 & nd & nd \\
\hline Neoptilota densa & 0.2 & 0.2 & 0 & 0.1 & 0 & nd & nd \\
\hline Fryeella gardneri & 0.2 & $\mathbf{0}$ & 0 & 0 & 0 & nd & nd \\
\hline Clear substratelnongeniculate corallines & 7.9 & 9 & 9.9 & 6.2 & 17.9 & ns & $\mathrm{ns}$ \\
\hline Sand & 1.6 & 0.8 & 1.7 & 1.4 & 2.9 & ns & $<0.01$ \\
\hline Total species/quadrat & $12^{*}$ & 10 & 9 & 9 & 9 & nd & nd \\
\hline Richness (\# species/quadrat) & 3.5 & 2.7 & 1.9 & 1.3 & 1.4 & $<0.01$ & ns \\
\hline \# with highest bottom cover in treatment & 9.5 & 3.5 & 2 & 0 & 2 & nd & nd \\
\hline$\%$ cover of patch gaps & na & 11.7 & 25.5 & na & 4.3 & nd & nd \\
\hline
\end{tabular}


cies richness tended to increase with increasing bottom light, but the trend was not significant (Spearman rank correlation: $\mathrm{r}=0.9 ; \mathrm{k}=5 ; \mathrm{p}=0.084$ ).

\section{DISCUSSION}

Few studies have simultaneously examined the effects of shading from both individual and combined kelp canopies (see Reed \& Foster 1984, Dayton et al. 1992). This experiment found that removal of the dominant kelp canopies lead to complex responses in the benthic light regimes and corresponding responses in the benthic algal communities. Higher cover of red algae in spring and subsequent decreases by late summer 1993 in all treatments with canopies (Fig. 3C) supports previous observations that understory plants undergo early spring growth before canopy layers mature (Pearse \& Hines 1979, Foster 1982, Breda \& Foster 1985, Collins et al. 1985, Harrold et al. 1988). The continued increase in cover of red algae through September 1993 in the no canopy treatment indicates that these algae have greater growth potential than was observed under the canopies, but shading causes their early declines in abundance.

The effects of increased bottom light in the no canopy treatment did not persist without the subsequent removal of the seasonal Desmarestia canopy. Desmarestia ultimately covered as much as $90 \%$ of the substrate in this treatment and reduced bottom light far below that observed in the unmanipulated canopy areas. This suggests that a single benthic canopy of Desmarestia is more effective at shading the bottom and influencing benthic algal composition than the combined surface and subsurface kelp canopies. Summertime benthic irradiance and understory algal composition in the Pterygophora canopy treatment was similar to that in the both canopies treatment, suggesting that the Pterygophora canopy, where present, is the dominant canopy regulating benthic algal composition. In contrast, in the absence of Pterygophora, the Macrocystis canopy was not able to reduce bottom light to levels similar to those observed under both canopy layers and was found to have greater red algal cover and species richness. Regardless, each canopy type, either individually or in combination, is capable of decreasing bottom light to levels that reduce recruitment of other species of macroalgae, including the dominant kelps themselves (Reed \& Foster 1984, Foster \& Schiel 1985, Dayton et al. 1992, Edwards 1998).

The canopy treatments also differed with regard to homogeneity and intensity of gap irradiance. Thus, while benthic irradiance varied as a function of canopy type (associated with capabilities to shade the understory), it also varied substantially as a function of canopy uniformity. In sum, our results show that shading from Macrocystis canopy provided a more uniform intermediate light environment $(45 \%$ of ambient in September 1993) and Pterygophora provided greater shading ( $2 \%$ of ambient in September 1993) but with greater heterogeneity (calculated $25 \%$ patch-gaps in September 1993).

Response to intermediate shading and canopy variability are evident within the 2 single canopy treatments (Tables $2 \& 3$ ). The greater species richness $(2.7$ species per quadrat) and intermediate algal cover (32\% fleshy red algae) of the Macrocystis canopy treatment in comparison to the control and Desmarestia canopy treatments suggest that a single canopy Macrocystis forest can support a greater abundance of turf algal species than a 2 canopy forest. As suggested by Kennelly (1987a), some species respond to clearing $50 \%$ of the canopy layer. Three such species have been identified here (Table 2). Because Pterygophora is capable of excluding light-adapted red algae by reducing irradiance by 20 times that measured under the Macrocystis canopy, holes (patch-gaps) within the canopy most likely provide favorable microhabitats for growth of these species under a single Macrocystis canopy.

Without a surface canopy of Macrocystis, these gaps within the Pterygophora would receive full ambient light and be dominated by Desmarestia (>15\% cover of Desmarestia in September 1993). The Desmarestia would decrease understory species abundance and diversity and negate higher light associated with gaps in single canopy treatments. This study suggests that the abundance and diversity of turf red algae within the natural 2 canopy environment of Stillwater Cove is most likely attained through variability in the Pterygophora canopy beneath a canopy of Macrocystis. Such a habitat allows increased light within Pterygophora patch-gaps sufficient for growth of the intermediate light-adapted red algae while restricting the dense Desmarestia canopy, which would recruit in the absence of a Macrocystis canopy and exclude a majority of red algal species.

One of the most surprising results of this study was the weak response of the red algae as a whole to the kelp clearings, a response that was only significant on the last sample date (December 1993). An inherent problem, however, with grouping large numbers of individual species when measuring a manipulative effect, is the masking of treatment differences from a variety of responses of separate taxa. The various responses of individual red algae in this study suggest that grouping algal species into broad groups such as total red algae can obscure rather than illuminate community organization regarding light requirements. The classification of species into functional groups is 
used to develop general models and to increase the statistical robustness of data. When applied in this study, this technique similarly masked important single species attributes and interactions. Several subgroups of understory algae responded differently to the canopy disturbance; such inferences were lost if the subgroups were combined within the commonly used total and fleshy red functional groups.

We found that grouping the individual species according to similarities in how they respond to changes in their environment enhanced the ability to discern community-level effects of the canopy manipulations, and we devote the remainder of our discussion to inferences drawn from this method.

Similar to observations in terrestrial forests, the most abundant understory species, namely geniculate coralline algae, Plocamium cartilagineum and Laurencia subopposita, did not exhibit marked responses to the canopy manipulations and were therefore categorized as light-flexible algae. Moreover, P. cartilagineum and L. subopposita are perhaps the foliose red algae best adapted to the understory environment of Stillwater Cove; they are relatively unaffected by low light regimes and they are both adapted to dispersal via dislodgement, fragmentation and subsequent entanglement with the coralline turf (Downing 1995), the single most abundant understory in the cove. In contrast, those species that increased substantially following the removal of the kelp canopies, namely Fauchea laciniata, Chondracanthus corymbifera, Prionitis lanceolata, Weeksia reticulata, Callophyllis crenulata, Rhodymenia californica and Cryptopleura farlowiana were categorized as light-adapted species. These species were more abundant and exhibited greater richness within the no canopy treatment than in any of the other treatments. Furthermore, by subdividing the light-adapted species into 2 subgroups, high-light and intermediate-light species, we were able to discern that some species responded to the removal of a single canopy layer (intermediate-light species) while others required the removal of both kelp canopy layers (high-light species). It is interesting that, other than an initial bleaching of encrusting and articulated corallines which recovered rapidly, no alga responded negatively (i.e. were classified as shade loving) to the clearing of canopy layers.

The various mechanisms by which the different species responded to the canopy clearings are unclear and may have varied from species to species. For example, Edwards (1998) observed that the increases in Desmarestia abundance following kelp-canopy removal was due to the enhanced recruitment of its sporophytes (by means of reproduction of its microscopic gametophytes; Edwards 2000), while Watanabe et al. (1992) observed that Pterygophora exhibited a positive physiological response (increased growth, fecundity and photosynthesis) following removal of the Macrocystis canopy. Similarly, Roberts (1996) observed that at least some red algae (e.g. Bossiella californica) can shift photosynthetic pigments throughout their thalli and alter reproductive patterns in response to changes in the light regime. Whether such abilities allow some species to shift from one response group to another is unclear, and we believe warrants further investigation.

The wide range in the responses of these various species of red algae foster a diverse and complex understory algal community in Stillwater Cove. To address such complex responses, it is necessary to not only fully describe the light regime within this multicanopy community, but also to more completely appreciate the differences in the way each species responds to changes in the light environment. While similar results on the effects of canopy shading have been observed in other studies, most notably the dramatic positive response of Desmarestia following the removal of both canopies (e.g. Foster 1982, Reed \& Foster 1984, Dayton et al. 1992, 1999, Edwards 1998), we believe our study is unique in that it offers greater insight into the complex nature of how multiple species, or groups of species, respond to canopy shading. As such, we argue that adopting the ecological response-group approach may elucidate otherwise cryptic responses by the benthic algal assemblages to changes in the canopy structure.

To adopt response groups composed of these species for future research, however, is premature. Independent studies testing the expected response to canopy removal (both single and multiple canopies) is warranted. These groupings may not hold true for different locations, different canopy structures, or for different depths. For instance, Kain (1987) classified Plocamium cartilagineum as a 'shade loving' species which failed to thrive under full irradiance at a depth of $0.5 \mathrm{~m}$. Further field experimentation (additional clearing experiments and transplants) and laboratory studies are necessary before such classifications are adopted for generalization of response. A primary conclusion of this study is that variation in response among species occurs and should be taken into account to properly understand the complexity of an understory algal assemblage.

While this study was designed to investigate the competitive effects of canopy shading, other competitive effects were also apparent. The limited community changes after canopy removal (still dominated by geniculate corallines, Plocamium cartilagineum and Laurencia subopposita) suggests that shading is not the only factor structuring this system. The effects of proximity of spore sources, grazer abundance, substrate availability, sand cover, etc. likely also affect algal distribution and abundance, as has been 
observed in other studies (e.g. Foster 1982, Reed et al. 1988, Dayton et al. 1992, 1999, Edwards 1998). The reduction in red algal abundance from the 1992 Aplysia californica recruitment episode demonstrates the importance of rare but intense grazing events on understory composition. While some of the observations are speculative, the species response trend characterized in this study does add insight into the relative importance of other processes regulating this kelp forest system, and calls for further investigation. While variability within the understory assemblage does not allow for competitive exclusion of these species, significantly lower abundance under canopy layers are evident.

Acknowledgements. We thank our field assistants C. Roberts, B. Konar, J. Downing, G. Leonard, B. Colvin, L. Honma, S. Lamerdin, P. Brown and D. Steller for their many hours of underwater service. D. Reed and M. Graham provided insightful comments. Kelp canopy data were kindly provided by D. Glantz (Kelco, ISP Alginates, San Diego, CA). Access to the study sites was made possible by the Pebble Beach Corporation and Moss Landing Marine Laboratories. Helpful comments were provided by 2 anonymous reviewers. This work was funded, in part, by grants from the Dr. Earl H. and Ethyl M. Meyers Oceanographic and Marine Biology Trust and the Packard Foundation.

\section{LITERATURE CITED}

Breda VA, Foster MS (1985) Composition, abundance, and phenology of foliose red algae associated with 2 central California kelp forests. J Exp Mar Biol Ecol 94:15-130

Brokaw NVL, Scheiner SM (1989) Species composition in gaps and structure of tropical forests. Ecology 70:538-541

Canham CD (1989) Different responses to gaps among shadetolerant tree species. Ecology 70:569-576

Cecchi LB, Cinelli F (1992) Canopy removal experiments in Cystoseira-dominated rockpools from the western coast of the Mediterranean (Ligurian Sea). J Exp Mar Biol Ecol 15: 569-583

Clark RP (1996) The effects of shade from multiple kelp canopies on understory algal composition. MS thesis, San Francisco State University, CA

Collins BS, Dunne KP, Pickett TA (1985) Responses of forest herbs to canopy gaps. In: Pickett ST, White PS (eds) The ecology of natural disturbance and patch dynamics. Academic Press, Orlando, FL, p 218-234

Connell JH (1989) Some processes affecting the species composition in forest gaps. Ecology 70:560-562

Cowen RK, CR Agegian, Foster MS (1982) The maintenance of community structure in a central California giant kelp forest. J Exp Mar Biol Ecol 64:189-201

Dayton PK, Currie V, Gerrodette TB, Keller D, Rosenthal R, VanTresca D (1984) Patch dynamics and stability of some California kelp communities. Ecol Monogr 54:253-289

Dayton PK, Tegner MJ, Parnell PE, Edwards PB (1992) Temporal and spatial patterns of disturbance and recovery in a kelp forest community. Ecol Monogr 62:421-445

Dayton PK, Tegner MJ, Edwards PB, Riser KL (1999) Temporal and spatial scales of kelp demography: the role of oceanographic climate. Ecol Monogr 69:219-250

Dethier MN, Graham ES, Cohen S, Tear LM (1993) Visual versus random-point percent cover estimations: 'objective' is not always better. Mar Ecol Prog Ser 96:93-100

Downing JW (1995) The effects of vegetative reproduction on the recruitment and small scale distribution of the red alga Plocamium cartilagineum. MSc thesis, San Francisco State University, CA

Edwards MS (1998) Effects of long-term kelp canopy exclusion on the abundance of the annual alga Desmarestia ligulata (Light F). J Exp Mar Biol Ecol 228:309-326

Edwards MS (2000) The role of alternate life-history stages of a marine macroalga: a seed bank analogue? Ecology 81: $2404-2415$

Edwards MS (2001) Scale-dependent patterns of community regulation in giant kelp forests. $\mathrm{PhD}$ thesis, University of California, Santa Cruz, CA

Edwards MS (2004) Estimating scale-dependency of disturbance impacts: El Niños and giant kelp in the northeast Pacific. Oecologia 138:436-447

Foster MS (1975a) Algal succession in a Macrocystis pyrifera forest. Mar Biol 32:313-329

Foster MS (1975b) Regulation of algal community development in the Macrocystis pyrifera forest. Mar Biol 32: $331-342$

Foster MS (1982) The regulation of macroalgal associations in kelp forests. In: Srivastava L (ed) Synthetic and degradative processes in marine macrophytes. Walter de Gruyter, Berlin

Foster MS, Schiel DR (1985) The ecology of giant kelp forests in California: a community profile. Biol Rep US Fish Wildl Serv 85:1-152

Gerard VA (1984) The light environment in a giant kelp forest: influence of Macrocystis pyrifera on spatial and temporal variability. Mar Biol 84:189-195

Goodall DW (1952) Some considerations in the use of point quadrats for the analysis of vegetation. Aust J Sci Res Ser 5:1-41

Graham MH (1996) Effect of high irradiance on recruitment of the giant kelp Macrocystis (Phaeophyta), in shallow water. J Phycol 32:903-906

Graham MH (1997) Factors determining the upper limit of giant kelp, Macrocystis pyrifera Agardh, along the Monterey Peninsula, central California, USA. J Exp Mar Ecol 218:127-149

Greig-Smith P (1983) Studies in ecology: quantitative plant ecology, Vol 9. University of California Press, Berkeley, $\mathrm{CA}$

Harrold CJ, Watanabe J, Lisin S (1988) Spatial variation in the structure of kelp forest communities along a wave exposure gradient. PSZN I: Mar Ecol 9:131-156

Hay ME (1994) Species as 'noise' in community ecology: Do seaweeds block our view of the kelp forest? Trends Ecol Evol 9:414-416

Hilborn R, Mangel M (1997) The ecological detective confronting models with data. Princeton University Press, Princeton, NJ

Hubbell SP, Foster RB, O'Brien ST, Harms KE, Condit R, Welchsler B, Wright SJ, Loo se Lao S (1999) Light-gap disturbances, recruitment limitation, and tree diversity in a neotropical forest. Science 283:554-557

Kain JM (1987) Seasonal growth and photoinhibition in Plocamium cartilagineum (Rhodophyta) off the Isle of Man. Phycologia 26:88-99

Kastendiek J (1982) Competitor-mediated coexistence: interactions among three species of benthic macroalgae. J Exp Mar Biol Ecol 62:201-210 
Kennelly SJ (1987a) Physical disturbances in an Australian kelp community. II. Effects on understorey species due to differences in kelp cover. Mar Ecol Prog Ser 40:155-165

Kennelly SJ (1987b) Physical disturbances in an Australian kelp community. I. Temporal effects. Mar Ecol Prog Ser 40: 145-153

Kennelly SJ (1989) Effects of kelp canopies on understory species due to shade and scour. Mar Ecol Prog Ser 50:215-224

Kimura RS, Foster MS (1984) The effects of harvesting Macrocystis pyrifera on the algal assemblage in a giant kelp forest. Hydrobiologia 17:425-428

Konar B, Foster MS (1992) Distribution and recruitment of subtidal geniculate coralline algae. J Phycol 28:273-280

Kursar TA, Coley PD (1999) Contrasting modes of light acclimation in two species of the rain forest understory. Oecologia 121:489-498

Leonard GH, Clark RP (1993) Point quadrat versus video transect estimates of the benthic red algae. Mar Ecol Prog Ser 101:203-208

Littler MM, Littler DS (1980) The evolution of thallus form and survival strategies in benthic marine macroalgae: field and laboratory tests of a functional form model. Am Nat 116:25-44

McCullagh P, Nelder JA (1989) Generalized linear models. Chapman \& Hall, London

Padilla DK, Allen BJ (2000) Paradigm lost: reconsidering functional form and group hypotheses in marine ecology. J Exp Mar Biol Ecol 250:207-221

Pearse JS, Hines AH (1979) Expansion of central California kelp forests following the mass mortality of sea urchins. Mar Biol 51:83-91

Peres-Neto PR (1999) How many statistical tests are too many? The problem of conducting multiple ecological inferences revisited. Mar Ecol Prog Ser 176:303-306

Editorial responsibility: Antony Underwood (Contributing Editor), Sydney, Australia
Pickett ST, White PS (1985) The ecology of natural disturbances and patch dynamics. Academic Press, Orlando, FL

Reed DC, Foster MS (1984) The effects of canopy shading on algal recruitment and growth in a giant kelp forest. Ecology 65:937-948

Reed DC, Laur DR, Ebeling AW (1988) Variation in algal dispersal and recruitment: the importance of episodic events. Ecol Monogr 58:321-335

Roberts CA (1996) Light and plant orientation effects in pigment and reproductive patterns in Bossiella sp. MSc thesis, San Jose State University, CA

Santelices B, Ojeda FP (1984) Effects of canopy removal on the understory algal community structure of coastal forests of Macrocystis pyrifera from southern South America. Mar Ecol Prog Ser 14:165-173

Schiel DR, Foster MS (1986) The structure of subtidal algal stands in temperate waters. Oceanogr Mar Biol Annu Rev 24:265-307

Seymore RJ, Tegner MJ, Dayton PK, Parnell PE (1989) Storm wave induced mortality of giant kelp, Macrocystis pyrifera, in southern California. Estuar Coast Shelf Sci 28: $277-292$

Simes RJ (1986) An improved Bonferroni procedure for multiple tests of significance. Biometrika 73:751-754

Spies TA, Franklin JF (1989) Gap characteristics and vegetation response in coniferous forests of the Pacific Northwest. Ecology 70:543-545

Watanabe JM, Phillips RE, Allen NH, Anderson WA (1992) Physiological response of the stipitate kelp, Pterygophora californica Ruprecht, to shading by the giant kelp, Macrocystis pyrifera C. Agardh. J Exp Mar Biol Ecol 159: $237-252$

Whitmore TC (1989) Canopy gaps and the two major groups of forest trees. Ecology 70:569-576

Submitted: September 4, 2003; Accepted: October 22, 2003 Proofs received from author(s): February 2, 2004 